\title{
High CD204+ tumor-infiltrating macrophage density predicts a poor prognosis in patients with urothelial cell carcinoma of the bladder
}

\author{
Bo Wang ${ }^{1,2, *}$, Hao Liu' ${ }^{2, *}$, Xiaoliang Dong ${ }^{1, *}$, Shaoxu Wu², Hong Zeng ${ }^{3}$, Zhuowei Liu ${ }^{4}$, \\ Di Wan', Wen Dong ${ }^{2}$, Wang He ${ }^{2}$, Xu Chen ${ }^{2}$, Limin Zheng ${ }^{5}$, Jian Huang ${ }^{2}$, Tianxin Lin ${ }^{1,2}$ \\ ${ }^{1}$ Guangdong Provincial Key Laboratory of Malignant Tumor Epigenetics and Gene Regulation, Sun Yat-Sen Memorial Hospital, \\ Sun Yat-Sen University, Guangzhou, PR China \\ ${ }^{2}$ Department of Urology, Sun Yat-Sen Memorial Hospital, Sun Yat-Sen (Zhosngshan) University, Guangzhou, PR China \\ ${ }^{3}$ Department of Pathology, Sun Yat-Sen Memorial Hospital, Sun Yat-Sen (Zhongshan) University, Guangzhou, PR China \\ ${ }^{4}$ Department of Urology, Cancer Center, Sun Yat-Sen (Zhongshan) University, Guangzhou, PR China \\ ${ }^{5}$ State Key Laboratory of Oncology in South China, Cancer Center, Sun Yat-Sen (Zhongshan) University, Guangzhou, PR China \\ *These authors have contributed equally to this work
}

Correspondence to:

Tianxin Lin, e-mail: tianxinl@sina.com

Jian Huang, e-mail: urolhj@sina.com

Keywords: tumor-infiltrating macrophages, CD204, CD 169, urothelial cell carcinoma of the bladder (UCB)

Received: December 03, $2014 \quad$ Accepted: April 25, $2015 \quad$ Published: May 07, 2015

\section{ABSTRACT}

Macrophages (MQs) are a major cell type that can infiltrate solid tumors and exhibit distinct phenotypes in different tumor microenvironments. This study attempted to investigate the prognostic values of various tumor-infiltrating $М \varphi$ phenotypes in patients with urothelial cell carcinoma of the bladder (UCB), with a focus on $M \varphi$ tissue microlocalization. M $\varphi s$ were assessed by immunohistochemistry in tissues from 302 UCB patients using CD68 as a pan-MФ marker, and CD204 and CD169 as robust pro- and anti-tumoral M $\varphi$ phenotype markers, respectively. Our data showed that these $M \varphi$ phenotypes were predominately distributed in stromal (ST) rather than in intratumoral (INT) regions (all $P<0.0001$ ). Surprisingly, CD204 and CD169 can be co-expressed by the same CD68+ MQSs. Kaplan-Meier analysis revealed that all INT- and ST-infiltrating CD204+ or CD169+ $M \varphi$ densities were inversely associated with overall survival (all $P<0.01$ ). By multivariate analysis, ST-infiltrating CD204 ${ }^{+} M \varphi$ density emerged as an independent prognostic factor for overall survival (HR, 1.981; $P=0.022$ ). Moreover, the density of ST-infiltrating CD204 ${ }^{+}$M $\varphi$ s was positively associated with the tumor size $(P=0.001)$, tumor stage $(P<0.0001)$, nodal metastasis $(P<0.0001)$, and histological grade $(P<0.0001)$. Our findings suggest that CD204+ M predominant $M \varphi$ phenotype in human bladder cancer.

\section{INTRODUCTION}

Bladder cancer is the most common type of urological tumor and more than $90 \%$ of patients present as urothelial cell carcinoma of the bladder (UCB) [1-2]. The intravesical instillation of bacillus Calmette-Guerin has been used as an effective immunotheraputic strategy to prevent recurrence and progression in selected patients with non-muscle-invasive bladder cancer [2-4], suggesting that UCB is a potentially immunogenic type of tumor.
Tumor progression has been recognized to be the product of crosstalk that evolves between different cell types within tumors [5-6]. Tumor-infiltrating macrophages (M $\varphi s)$ have been shown to have both pro- and antitumorigenic functions, which could be a consequence of the different tumor microenvironments that promote their differentiation into distinct subpopulations [7-8]. In mice, diverse $\mathrm{M} \varphi$ subpopulations can be distinguished based on the expression of several specific markers [9]. However, many markers that have been used to identify murine $\mathrm{M} \varphi s$ 
cannot be translated to differentiate human $\operatorname{M\varphi s}[7,9]$. $\mathrm{CD} 68$, a pan-M $\varphi$ marker, is widely used to evaluate $\mathrm{M} \varphi$ density in diverse types of human tumors; however, the expression of CD68 does not allow for discrimination between diverse $\mathrm{M} \varphi$ phenotypes, which can be associated with different patient prognosis [10-13]. In breast cancer, $\mathrm{CD} 68^{+} \mathrm{M} \varphi s$ can be categorized into two subgroups based on thymidine phosphorylase (TP) that are associated with strikingly different prognosis: a $\mathrm{TP}^{+} \mathrm{M} \varphi$ group that shows a poor prognosis and a $\mathrm{TP}^{-} \mathrm{M} \varphi$ group that shows a good prognosis [12]. In renal cell carcinoma, combined analysis of CD11 $\mathrm{c}^{+} \mathrm{M} \varphi \mathrm{s}$ and $\mathrm{CD} 206^{+} \mathrm{M} \varphi s$ can more accurately predict patient outcomes compared to analysis of $\mathrm{CD} 68^{+} \mathrm{M} \varphi \mathrm{s}$ alone [13]. Therefore, a more detailed characterization of distinct $\mathrm{M} \varphi$ subpopulations might provide an opportunity to eliminate protumoral $\mathrm{M} \varphi$ s or harness antitumoral $\mathrm{M} \varphi \mathrm{s}$ in human cancers.

CD204, also known as scavenger receptor $\mathrm{A}$, is a phagocytic pattern-recognition receptor that is primarily expressed on myeloid lineage cells and is involved in homeostatic functions, such as lipid metabolism and phagocytosis [14]. Emerging evidence has shown that the tumor microenvironment can cause the upregulation of CD204 expression on M $\varphi$ s. Furthermore, a high density of tumor-infiltrating CD204 $4^{+} \mathrm{M} \varphi$ s is associated with worse patient outcomes in various types of cancer [15-17]. Additionally, CD169, a member of the sialic-acid-binding immunoglobulin-like lectin family, is expressed on myeloid lineage cells, notably on subpopulations of tissue resident M $\varphi s$ and inflammatory M $\varphi s$ in mice and humans [1819]. A recent study showed that $\mathrm{CD} 169^{+} \mathrm{M} \varphi$ s dominate antitumor immunity by cross-presenting tumor antigens to $\mathrm{CD}^{+} \mathrm{T}$ cells [20]. Taken together, these observations

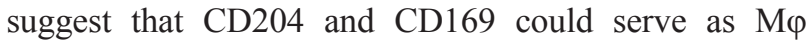
subpopulation markers and that they might aid the design of novel anti-tumor vaccines. To date, very little is known about the density, localization, and clinical relevance of $\mathrm{CD} 204^{+} \mathrm{M} \varphi s$ and CD169 ${ }^{+} \mathrm{M} \varphi s$ in human bladder cancer.

Herein, we investigated the distribution and

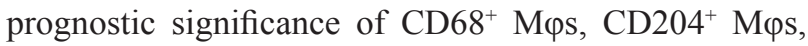

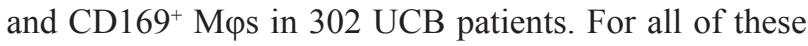
$\mathrm{M} \varphi$ phenotypes, a trend for localization in stromal (ST) rather than in intratumoral (INT) regions of UCB tissues, as well as a higher frequency of ST-infiltrating CD204 $\mathrm{M} \varphi s$, could predict a poor prognosis, independent of other tumor-infiltrating $\mathrm{M} \varphi$ phenotypic markers and clinical variables. Our data suggest that CD204+ M $\varphi$ s can play protumoral roles that are detrimental and could represent the predominant $\mathrm{M} \varphi$ phenotype in human bladder cancer.

\section{RESULTS}

\section{Immunohistochemical characteristics}

M $\varphi s$ exhibit diverse phenotypes during inflammation and tumor pathogenesis [21-22]. To evaluate $\mathrm{M \varphi}$ phenotypes and distribution patterns in human UCB tissues, we used immunostaining to study $\mathrm{CD}^{2} 8^{+} \mathrm{M} \varphi s$, $\mathrm{CD}_{204^{+}} \mathrm{M} \varphi s$, and CD169 ${ }^{+} \mathrm{M} \varphi s$ in situ. Clear and distinguishable staining was evident for both CD68 and each $\mathrm{M} \varphi$ phenotype marker (Fig. 1). Using two-color immunofluorescence analyses, we also observed that $\mathrm{CD} 204^{+} \mathrm{M} \varphi \mathrm{s}$ and $\mathrm{CD} 169^{+} \mathrm{M} \varphi s$ could be observed among the $\mathrm{CD}^{6} 8^{+} \mathrm{M} \varphi \mathrm{s}$ (Supplementary Fig. 1).

Previous studies showed that M $\varphi$ s could be detected in different locations within and around a tumor [7, 11]. We also found that $\mathrm{CD}^{2} 8^{+} \mathrm{M} \varphi \mathrm{s}$ were distributed throughout the tissues, and were more frequent in ST than in INT regions of UCB tissues ( $35 \pm 26$ and $15 \pm 14$ cells/field, respectively; Fig. $1 ; n=302$ ). Moreover, the frequencies of both CD204 $4^{+} \mathrm{M} \varphi$ s and CD $169^{+} \mathrm{M} \varphi s$ were significantly higher in ST regions $(24 \pm 36$ and $31 \pm 20$ cells/field, respectively) than in the corresponding INT regions of UCB tissues ( $13 \pm 16$ and $4 \pm 9$ cells/field, respectively). These findings indicated that $\mathrm{CD} 204^{+} \mathrm{M} \varphi s$ and CD169+ $\mathrm{M} \varphi s$ show the same localization bias as $\mathrm{CD}^{+} \mathrm{M} \varphi \mathrm{s}$ in UCB tissues (both $P<0.0001$; Fig. 1C).

To analyze potential associations between cell

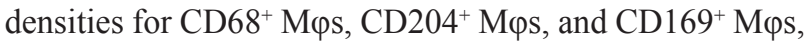
Spearman's rank correlation coefficients were calculated (Supplementary Table 1). The densities of all three markers were positively associated with each other in INT and associated ST regions, except for the association between $\mathrm{CD} 204^{+}{ }_{\mathrm{INT}} \mathrm{M} \varphi s$ and $\mathrm{CD} 169^{+}{ }_{\mathrm{ST}} \mathrm{M} \varphi \mathrm{s}(P=0.066)$. Using triple color immunofluorescence analyses, we also observed that CD204 and CD169 can be co-expressed on the same M $\varphi s$ in both INT and ST regions of UCB tissues (Fig. 2).

\section{Survival analysis}

To investigate the association of diverse $\mathrm{M \varphi}$ phenotypes with UCB progression, we divided 302 UCB patients into two groups based on the median frequencies of $\mathrm{CD}^{2} 8^{+} \mathrm{M} \varphi s, \mathrm{CD} 204^{+} \mathrm{M} \varphi s$, and $\mathrm{CD} 169^{+} \mathrm{M} \varphi \mathrm{s}$, respectively. Kaplan-Meier survival curves were then plotted to further investigate associations with survival (Fig. 3). The log-rank statistic was used to compare survival rates. We did not detect any association between OS and $\mathrm{CD}^{+} 8^{+}{ }_{\text {INT }} \mathrm{M} \varphi$ density $(P=0.19$, Fig. 3A), but we found a marked negative association between OS and the densities of $\mathrm{CD} 68^{+}{ }_{\mathrm{ST}} \mathrm{M} \varphi \mathrm{s}(P=0.0003$, Fig. 3B), $\mathrm{CD}^{204^{+}}{ }_{\text {INT }} \mathrm{M} \varphi \mathrm{s}(P=0.0008$, Fig. 3E $), \mathrm{CD} 204^{+}{ }_{\mathrm{ST}} \mathrm{M} \varphi \mathrm{s}$ $\left(P=0.003\right.$ Fig. 3F), CD169 ${ }^{+}{ }_{\text {INT }}$ M $\varphi s(P=0.005$, Fig. 3I $)$, and $\mathrm{CD}_{169^{+}}{ }_{\mathrm{sT}} \mathrm{M} \varphi \mathrm{s}(P<0.0001$, Fig. 3J $)$. However, the presence of these cells did not show any prognostic significance for RFS (all $P>0.05$, Fig. 3C-3D, 3G-3H, 3K-3L, Supplementary Table 2). After dichotomization at the median cell density for the pan-M $\varphi$ marker and M $\varphi$ markers for each activation phenotype, the 5-year OS rate was $71 \%$ above the median compared to $90 \%$ below the median for $\mathrm{CD} 8^{+}{ }_{\mathrm{ST}} \mathrm{M} \varphi \mathrm{s}, 74 \%$ vs. $87 \%$ for 
A
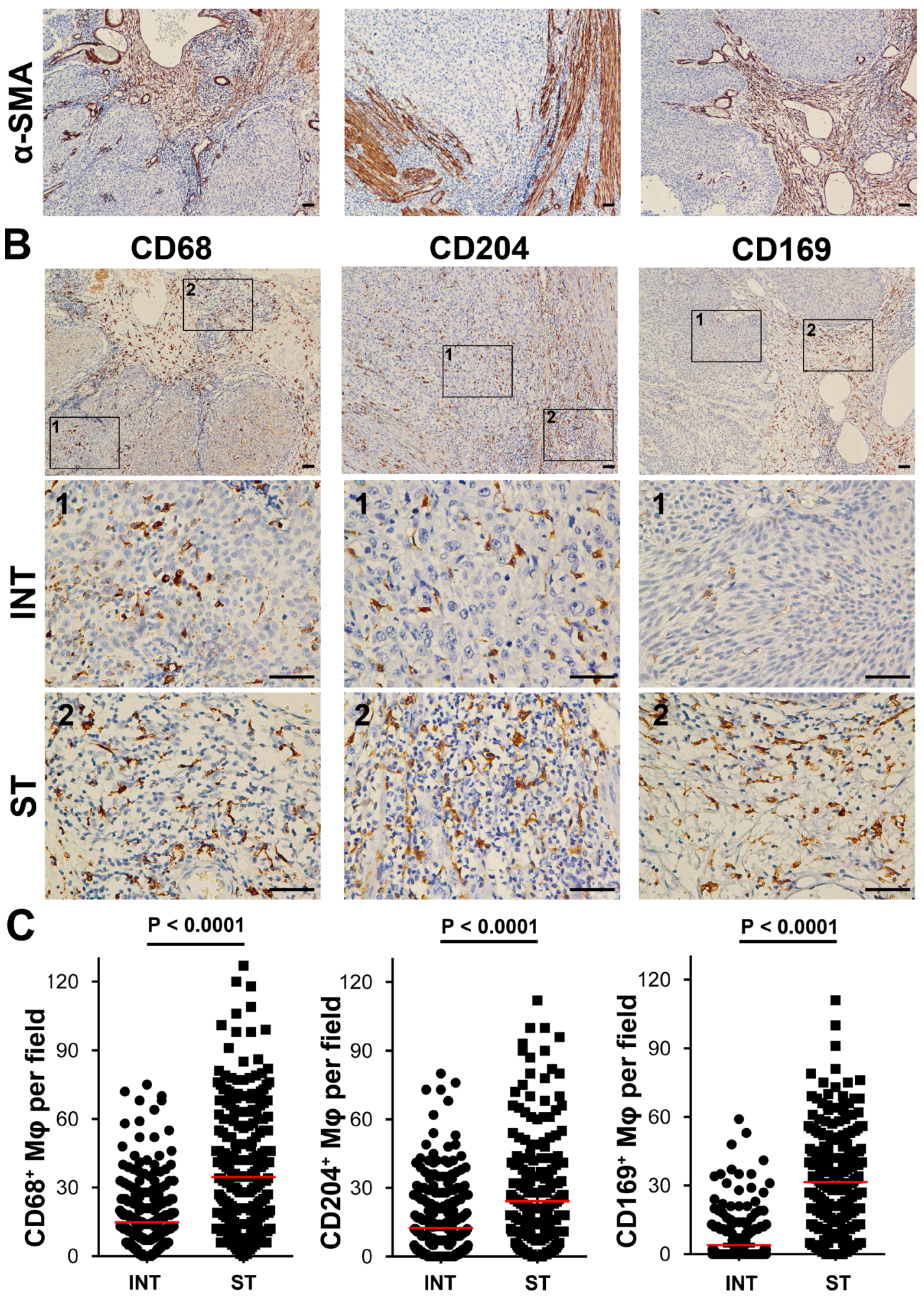

Figure 1: $\mathrm{CD}^{+} \mathrm{M} \varphi s, \mathrm{CD}^{+}{ }^{+} \mathrm{M} \varphi s$, and $\mathrm{CD}^{+69^{+}} \mathrm{M} \varphi s$ were enriched in the stromal regions of UCB tissues $(n=302)$. A. Anti- $\alpha$-SMA staining was used to distinguish intratumoral (INT) from stromal (ST) regions. B. Representative immunohistochemistry images of $\mathrm{CD}_{68}{ }^{+} \mathrm{M} \varphi \mathrm{s}, \mathrm{CD} 204^{+} \mathrm{M} \varphi s$, and $\mathrm{CD} 169^{+} \mathrm{M} \varphi$ s in human UCB tissues. The micrographs at higher magnification show stained INT (1) and ST (2) regions. Scale bar, $100 \mu \mathrm{m}$. C. The numbers of CD68 $8^{+} \mathrm{M} \varphi \mathrm{s}, \mathrm{CD} 204^{+} \mathrm{M} \varphi \mathrm{s}$, and CD169 ${ }^{+} \mathrm{M} \varphi \mathrm{s}$ in the INT and ST regions of human UCB tissues. Cell numbers were calculated as the cell count per $\times 400$ field. Data are expressed as means \pm SEM. 
CD204

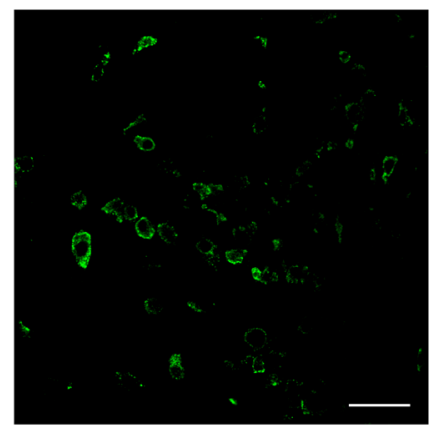

CD169

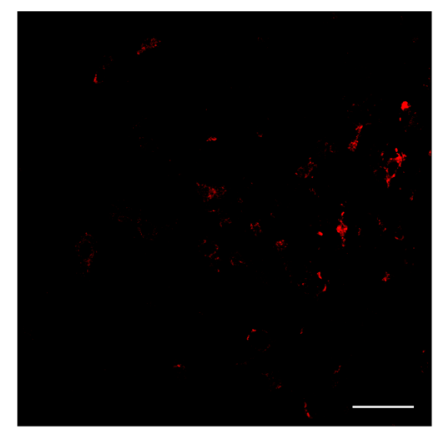

CD68

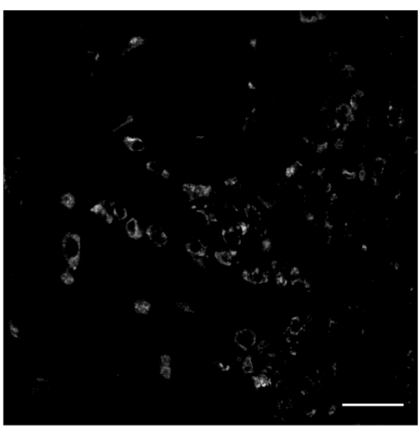

Merge

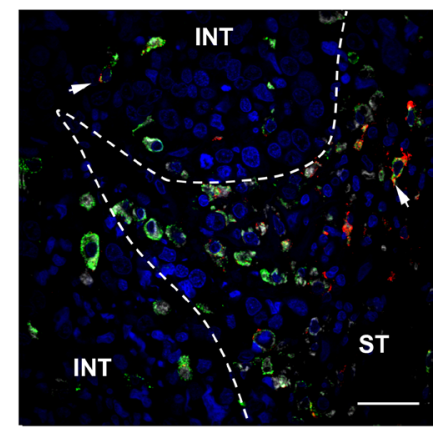

Figure 2: CD169 and CD204 can be co-expressed on the same M $\varphi$ s in UCB tissues. Paraffin-embedded UCB tissues $(n=5)$ were subjected to three-color immunofluorescence for CD204 (green), CD169 (red), and CD68 (gray), along with a DAPI counterstain (blue). While both CD204 cells and CD169 ${ }^{+}$cells are CD68 $8^{+} \mathrm{M} \varphi \mathrm{s}, \mathrm{CD} 204$ and CD169 could colocalize on cells in both intratumoral (INT) and stromal (ST) regions (white arrows). Scale bar, $20 \mu \mathrm{m}$.

$\mathrm{CD}^{204^{+}}{ }_{\text {INT }} \mathrm{M} \varphi \mathrm{s}, 70 \%$ vs. $91 \%$ for CD $204^{+}{ }_{\mathrm{ST}} \mathrm{M} \varphi \mathrm{s}, 68 \%$ vs. $85 \%$ for $\mathrm{CD} 169^{+}{ }_{\text {INT }} \mathrm{M} \varphi$ s and $71 \%$ vs. $89 \%$ for $\mathrm{CD} 169^{+}{ }_{\mathrm{ST}}$ Mps. When the clinicopathological variables that were significant in the univariate analysis were adopted as covariates (Table 1), multivariate analysis revealed that the density of CD204 ${ }_{\mathrm{ST}}^{+} \mathrm{M} \varphi$ s was an independent prognostic factor for $\mathrm{OS}(\mathrm{HR}, 1.981 ; P=0.022)$.

To further evaluate the prognostic value of CD204 ${ }_{\mathrm{ST}}^{+}$ $\mathrm{M} \varphi s$ in different UCB patient subgroups, patients were stratified according to age (Fig. 4A-4B), tumor size (Fig. 4C-4D), tumor stage (Fig. 4E-4F), and histological grade (Fig. 4G-4H). The density of $\mathrm{CD}_{204^{+}} \mathrm{ST} \mathrm{M} \varphi \mathrm{s}$ maintained its prognostic value in predicting a shorter OS in all of these subgroups, except for OS in patients who had a tumor size greater than $3 \mathrm{~cm}(P=0.29)$. Therefore, CD204 ${ }_{\mathrm{ST}}^{+} \mathrm{M} \varphi \mathrm{s}$ could represent a powerful prognostic factor for patients with UCB in different risk groups.

\section{The association of $\mathrm{CD204}_{\mathrm{ST}}^{+}$macrophage density and clinicopathological variables}

The correlation between $\mathrm{CD} 204^{+}{ }_{\mathrm{ST}} \mathrm{M} \varphi$ density and clinicopathological variables was further evaluated by $\mathrm{c}^{2}$ analysis (Table 2). The density of CD204 ${ }_{\text {ST }}^{+}$M $\varphi$ s was positively associated with tumor size $(P=0.001)$, tumor stage $(P<0.0001)$, nodal metastasis $(P<0.0001)$, and histological grade $(P<0.0001)$. These findings indicate that large tumors, high TNM stage, and poorly differentiated UCB are risk factors that favor the infiltration of CD204+ M 2 s in the ST of UCB tissues.

\section{DISCUSSION}

M $\varphi$ s are versatile, plastic cells that can respond to microenvironmental signals and display a broad spectrum of different phenotypes in human tumors
[10, 21-22]. Therefore, we investigated the distribution of $\mathrm{M} \varphi$ phenotypes in different microlocalizations within tumors and assessed their prognostic significance in UCB patients. We found that CD204 and CD169 are primarily expressed on $\mathrm{CD} 68^{ \pm} \mathrm{M} \varphi s$, and that they can be co-expressed on the same M $\varphi s$. All CD68 ${ }^{+} \mathrm{M} \varphi s, \mathrm{CD}_{204}{ }^{+}$ $\mathrm{M} \varphi s$, and $\mathrm{CD} 169^{+} \mathrm{M} \varphi s$ were found to be distributed throughout the tissue, but were often more prominent in $\mathrm{ST}$ than in INT regions in UCB tissues. Moreover, a high density of CD204 ${ }_{\mathrm{ST}}^{+} \mathrm{M} \varphi$ s could predict a poor prognosis for UCB patients and can be positively associated with tumor size, tumor stage, nodal metastasis, and histological grade. These data provide new insights into the significance of the location, density, and functional orientation of different immune cell populations in human tumor progression.

Previous studies have always used CD68 as a single immunohistochemical pan-M $\varphi$ marker to evaluate the location and density of $\mathrm{M} \varphi \mathrm{s}$ and their clinical relevance in bladder cancer, but the results have been conflicting [23-24]. In a study of 63 patients with bladder cancer, Nomura et al. reported that patients exhibiting a high tumor-infiltrating $\mathrm{M} \varphi$ density had worse postsurgical outcomes compared to those patients with a low tumorinfiltrating $\mathrm{M} \varphi$ density [23]. However, in another study that used tissue microarrays to analyze 296 bladder cancer tissues, Hoglund et al. observed that tumor-infiltrating $\mathrm{CD}_{68^{+}} \mathrm{M} \varphi$ density showed no association with patient survival [24]. These discrepancies are probably a consequence of differences in the number, stage, and size of tumors. Moreover, none of these studies evaluated the distribution of $M \varphi$ phenotypes within different microlocalizations.

Human tumor tissues can be anatomically classified into INT and ST regions, and each has distinct compositional and functional properties [25-26]. Therefore, we focused on the tissue microlocalization 

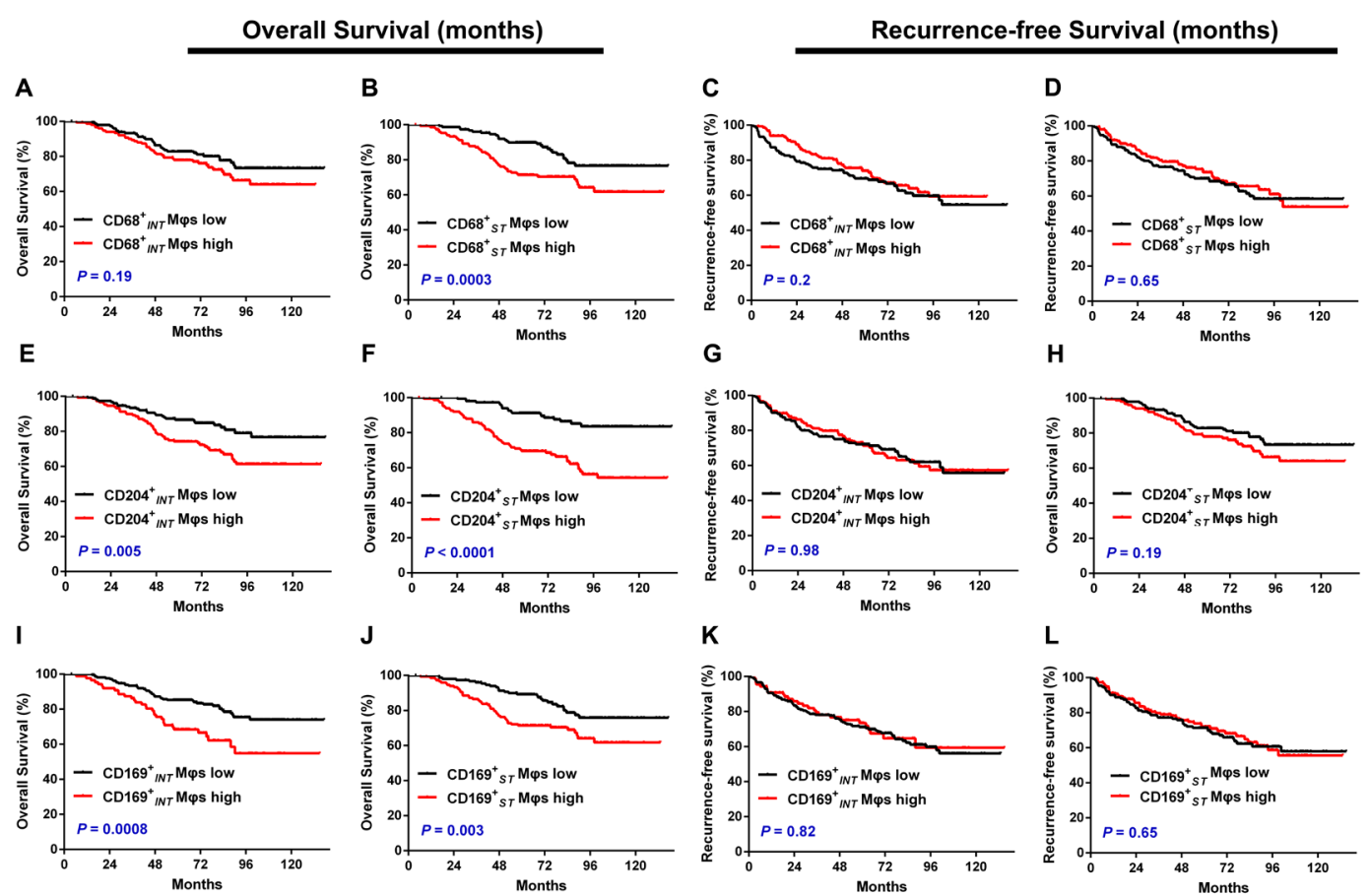

Figure 3: Cumulative overall survival and recurrence-free survival curves are shown for patients with $\mathrm{UCB}(n=$ 302). Kaplan-Meier survival estimates and log-rank tests were used to analyze the prognostic significance of $\mathrm{CD} 68^{+} \mathrm{M} \varphi \mathrm{s}, \mathrm{CD} 204^{+} \mathrm{M} \varphi \mathrm{s}$, and $\mathrm{CD} 169^{+} \mathrm{M} \varphi \mathrm{s}$ in intratumoral (INT) and stromal (ST) regions. Patients were divided into two groups according to the median number

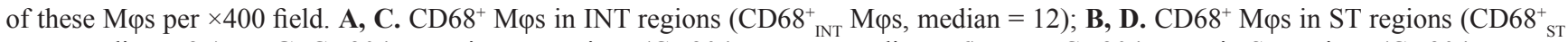
$\mathrm{M} \varphi \mathrm{s}$, median = 27); E, G. CD204 ${ }^{+} \mathrm{M} \varphi$ s in INT regions $\left(\mathrm{CD} 204^{+}{ }_{\mathrm{INT}} \mathrm{M} \varphi \mathrm{s}\right.$, median = 6); F, H. CD204 ${ }^{+} \mathrm{M} \varphi \mathrm{s}$ in ST regions $\left(\mathrm{CD} 204^{+}{ }_{\mathrm{ST}} \mathrm{M} \varphi \mathrm{s}\right.$, median = 12); I, K. CD $169^{+} \mathrm{M} \varphi \mathrm{s}$ in INT regions $\left(\mathrm{CD} 169^{+}{ }_{\mathrm{INT}} \mathrm{M} \varphi \mathrm{s}\right.$, median = 0); and $\mathbf{J}, \mathbf{L} . \mathrm{CD} 169^{+} \mathrm{M} \varphi \mathrm{s}$ in ST regions $\left(\mathrm{CD} 169^{+}{ }_{\mathrm{ST}} \mathrm{M} \varphi \mathrm{s}\right.$, median $=30.5$ ). Black lines, low group; red lines, high group.
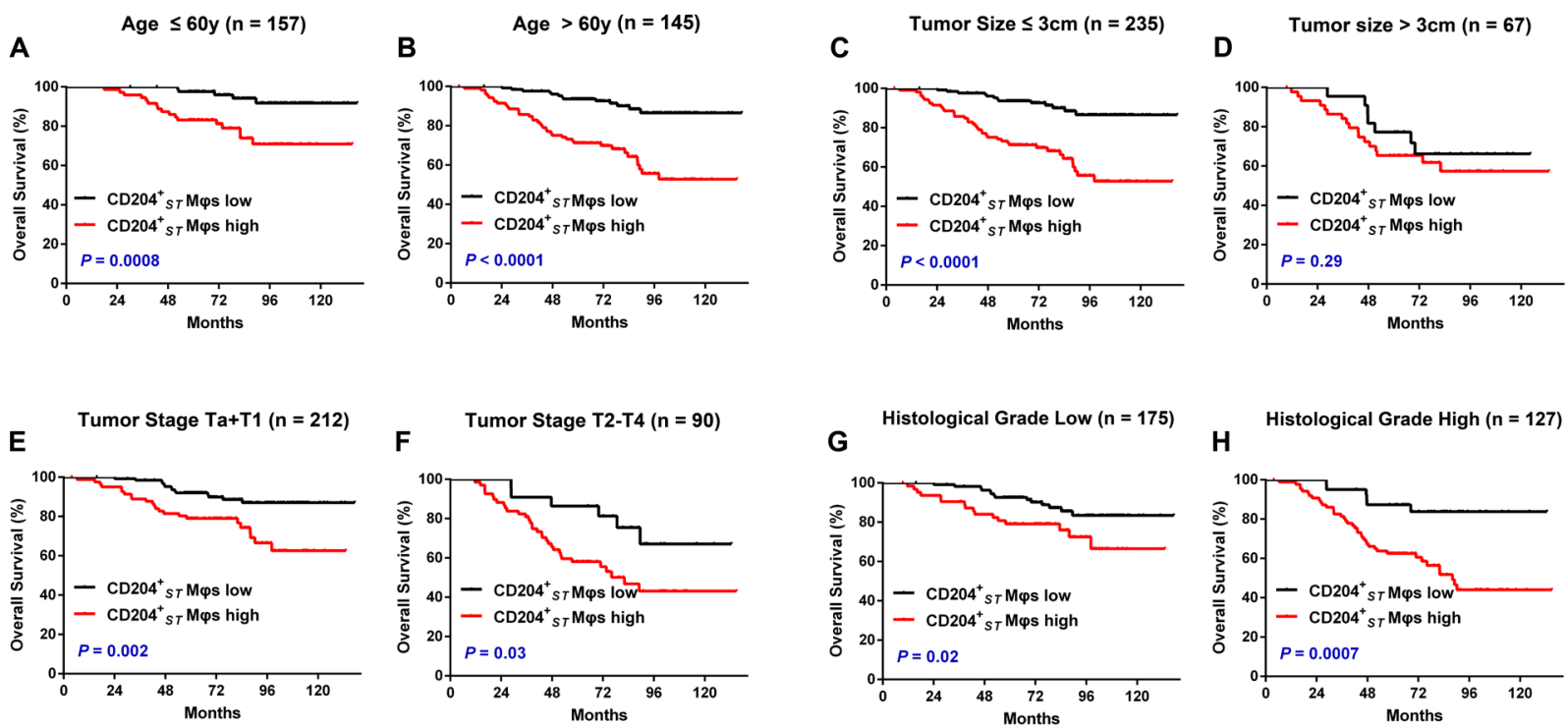

Figure 4: The accumulation of $\mathrm{CD204}^{+} \mathrm{M} \varphi s$ in stromal regions predicts a poor prognosis in different subgroups of UCB patients. Kaplan-Meier survival estimates and log-rank tests were used to analyze the prognostic significance of ST-infiltrating $\mathrm{CD} 204^{+} \mathrm{M} \varphi \mathrm{s}\left(\mathrm{CD} 204^{+}{ }_{\mathrm{ST}} \mathrm{M} \varphi \mathrm{s}\right)$ in each subgroup. All patients were stratified according to age A-B. tumor size C-D. tumor stage E-F. and histological grade $\mathbf{G - H}$. 
Table 1: Univariate and multivariate analysis of the factors associated with overall survival for UCB

\begin{tabular}{|c|c|c|c|c|c|c|}
\hline \multirow[b]{2}{*}{ Variable } & \multicolumn{3}{|c|}{ Univariate } & \multicolumn{3}{|c|}{ Multivariate } \\
\hline & HR & $95 \%$ CI & $P$ & HR & $95 \% \mathrm{CI}$ & $P$ \\
\hline $\begin{array}{l}\text { Age, years } \\
(>60 / \leq 60)\end{array}$ & 3.443 & $2.093-5.663$ & $1.1 \times 10^{-6}$ & 3.329 & $2.004-5.531$ & $<\mathbf{0 . 0 0 0 1}$ \\
\hline $\begin{array}{l}\text { Gender (female/ } \\
\text { male) }\end{array}$ & 0.672 & $0.309-1.46$ & 0.317 & & & NA \\
\hline $\begin{array}{l}\text { Tumor size } \\
(>3 \mathrm{~cm} / \leq 3 \mathrm{~cm})\end{array}$ & 1.785 & $1.1-2.895$ & 0.019 & 1.113 & $0.651-1.904$ & 0.696 \\
\hline $\begin{array}{l}\text { Multifocality } \\
\text { (Multifocal/ } \\
\text { Unifocal) }\end{array}$ & 0.876 & $0.526-1.46$ & 0.756 & & & NA \\
\hline $\begin{array}{l}\text { Tumor stage } \\
(\mathrm{T} 2-\mathrm{T} 4 / \mathrm{Ta}-\mathrm{T} 1)\end{array}$ & 3.001 & $1.913-4.71$ & $1.7 \times 10^{-6}$ & 1.915 & $1.071-3.422$ & 0.028 \\
\hline $\begin{array}{l}\text { Nodal metastasis } \\
\text { (N1-N2/N0) }\end{array}$ & 5.123 & $2.589-10.138$ & $2.7 \times 10^{-6}$ & 2.449 & $1.145-5.24$ & 0.021 \\
\hline $\begin{array}{l}\text { Histological grade } \\
\text { (High/Low) }\end{array}$ & 2.479 & $1.564-3.93$ & $1.1 \times 10^{-4}$ & 1.233 & $0.696-2.186$ & 0.473 \\
\hline $\begin{array}{l}\mathrm{CD} 68^{+}{ }_{\text {INT }} \mathrm{M} \varphi \mathrm{s} \\
\text { (High/Low) }\end{array}$ & 1.383 & $1.878-2.177$ & 0.162 & & & \\
\hline $\begin{array}{l}\mathrm{CD} 68^{+}{ }_{\mathrm{TT}} \mathrm{M} \varphi \mathrm{s} \\
\text { (High/Low) }\end{array}$ & 2.129 & $1.33-3.406$ & 0.002 & 0.91 & $0.527-1.572$ & 0.735 \\
\hline $\begin{array}{l}\mathrm{CD} 204^{+}{ }_{\mathrm{NNT}} \mathrm{M} \varphi \mathrm{s} \\
(\mathrm{High} / \mathrm{Low})\end{array}$ & 1.955 & $1.222-3.127$ & 0.005 & 1.042 & $0.59-1.84$ & 0.887 \\
\hline $\begin{array}{l}\mathrm{CD} 204^{+}{ }_{\text {ST }} \mathrm{M} \varphi s \\
\text { (High/Low) }\end{array}$ & 3.449 & $2.069-5.751$ & $2.2 \times 10^{-6}$ & 1.981 & $1.101-3.564$ & 0.022 \\
\hline $\begin{array}{l}\mathrm{CD} 169^{+}{ }_{\text {NNT }} \mathrm{M} \varphi \mathrm{s} \\
\text { (High/Low) }\end{array}$ & 2.145 & $1.358-3.389$ & 0.001 & 1.514 & $0.911-2.518$ & 0.11 \\
\hline $\begin{array}{l}\mathrm{CD} 169^{+}{ }_{\mathrm{ST}} \mathrm{M} \varphi \mathrm{s} \\
\text { (High/Low) }\end{array}$ & 2.009 & $1.26-3.202$ & 0.003 & 1.604 & $0.944-2.726$ & 0.08 \\
\hline
\end{tabular}

Abbreviations: UCB, urothelial cell carcinoma of the bladder; INT, intratumoral regions; ST, stromal regions; $\mathrm{CD}^{2} 8^{+}{ }_{\text {INT }}$ $\mathrm{M} \varphi s, \mathrm{CD}_{68^{+}} \mathrm{M} \varphi s$ in intratumoral regions; $\mathrm{CD} 8^{+}{ }_{\mathrm{ST}} \mathrm{M} \varphi s, \mathrm{CD} 68^{+} \mathrm{M} \varphi s$ in stromal regions; HR, hazard ratio; CI, confidence interval; NA, not applicable.

NOTE: Univariate and multivariate analysis. Cox proportional hazards regression model. Variables associated with survival by univariate analyses were adopted as covariates in multivariate analyses. Significant $P$-values are shown in bold font.

$\mathrm{HR}>1$, risk for death increased; $\mathrm{HR}<1$, risk for death reduced.

of $\mathrm{CD}_{68^{+}} \mathrm{M} \varphi s, \mathrm{CD} 204^{+} \mathrm{M} \varphi s$, and $\mathrm{CD} 169^{+} \mathrm{M} \varphi s$ in 302 patients with UCB. Our data showed that INT-infiltrating $\mathrm{CD}_{68}^{+} \mathrm{M} \varphi$ density showed no association with patient survival, but ST-infiltrating $\mathrm{CD}^{+} \mathrm{M} \varphi$ density was negatively associated with patient survival. In contrast to the conflicting prognistic significance of $\mathrm{CD}^{ \pm} 8^{ \pm} \mathrm{M} \varphi \mathrm{s}$ (pan-M $\varphi s$ ), both high INT- and ST-infiltrating CD204 ${ }^{+}$ $\mathrm{M} \varphi$ densities were found to be adverse signs in patients with UCB. Moreover, ST-infiltrating CD204+ M $\varphi$ density emerged as an independent predictor of prognosis and maintained its prognostic value to predict shorter survival with different risk groups in UCB patients. In accordance with our results, previous studies showed that a high density of tumor-infiltrating CD204+ ${ }^{+} \mathrm{M} \varphi$ s is associated with worse prognosis in renal, lung, and pancreatic cancers [15-17]. These findings suggest that CD204 ${ }^{+} \mathrm{M} \varphi \mathrm{s}$ could represent a stable and reliable prognostic indicator for UCB.

CD204 is cell-surface glycoprotein that belongs to the scavenger receptors with a protumoral function during 
Table 2: Associations between $\mathrm{CD204}_{\mathrm{ST}}^{+} \mathrm{M} \varphi$ density and the clinicopathological characteristics of UCB

$\mathrm{CD204}_{\mathrm{ST}}^{+} \mathrm{M} \varphi$ Density

\begin{tabular}{|c|c|c|c|c|}
\hline Variable & Low & High & $R$ & $P$ \\
\hline No. of patients & $151(50 \%)$ & $151(50 \%)$ & & \\
\hline Age, years & & & 0.086 & 0.135 \\
\hline$\leq 60$ & $85(28 \%)$ & $72(24 \%)$ & & \\
\hline$>60$ & $66(22 \%)$ & $79(26 \%)$ & & \\
\hline Gender & & & 0.039 & 0.499 \\
\hline Male & $133(44 \%)$ & $129(43 \%)$ & & \\
\hline Female & $18(6 \%)$ & $22(7 \%)$ & & \\
\hline Tumor size & & & 0.183 & 0.001 \\
\hline$\leq 3 \mathrm{~cm}$ & $129(43 \%)$ & $106(35 \%)$ & & \\
\hline$>3 \mathrm{~cm}$ & $22(7 \%)$ & $45(15 \%)$ & & \\
\hline Multifocality & & & 0 & 1 \\
\hline Unifocal & $107(35 \%)$ & $107(35 \%)$ & & \\
\hline Multifocal & $44(15 \%)$ & $44(15 \%)$ & & \\
\hline Tumor stage & & & 0.333 & $<0.0001$ \\
\hline $\mathrm{Ta}-\mathrm{T} 1$ & $129(43 \%)$ & $83(27 \%)$ & & \\
\hline $\mathrm{T} 2-\mathrm{T} 4$ & $22(7 \%)$ & $68(23 \%)$ & & \\
\hline Nodal metastasis & & & 0.207 & $<0.0001$ \\
\hline N0 & $150(50 \%)$ & $136(45 \%)$ & & \\
\hline $\mathrm{N} 1-\mathrm{N} 2$ & $1(0 \%)$ & $15(5 \%)$ & & \\
\hline Histological grade & & & 0.315 & $<0.0001$ \\
\hline Low & $111(37 \%)$ & $64(21 \%)$ & & \\
\hline High & $40(13 \%)$ & $87(29 \%)$ & & \\
\hline
\end{tabular}

Abbreviations: UCB, urothelial cell carcinoma of the bladder; $\mathrm{CD}_{204^{+}}{ }_{\mathrm{ST}} \mathrm{M} \varphi, \mathrm{CD} 204^{+} \mathrm{M} \varphi$ in stromal regions.

Significant $P$-values are shown in bold font.

tumor progression $[14,27]$. Studies of mouse models showed that the expression of CD204 helped dormant tumor cells to acquire invasiveness capability, and that loss of CD204 affected tumor metastasis at the initial inoculation site [27]. Consistent with these observations, our study showed that $\mathrm{CD} 204^{+} \mathrm{M} \varphi \mathrm{s}$ in ST regions were positively associated with tumor stage, nodal metastasis, and histological grade. Moreover, we observed that CD204 did not co-localize with immunosuppressive molecules, such as IL-10, B7-H1, or B7-H4, in UCB tissues (data not shown), which suggested that the expression of $\mathrm{CD} 204$ on M $\varphi$ s is sufficient to promote tumor progression independently of other pathways.

CD169 is a macrophage-restricted cell surface receptor with a profound regulatory effect on $\mathrm{T}$ cell tumoricidal responses, which suggested that $\mathrm{CD} 169^{+}$
M $\varphi s$ are antitumorigenic [19-20]. Using a hepatocellular carcinoma model system, the antitumoral role of $\mathrm{CD} 169^{+} \mathrm{M} \varphi \mathrm{s}$ could be further supported by the finding that $\mathrm{CD} 169^{+} \mathrm{M} \varphi \mathrm{s}$ exhibited an activated phenotype and promoted Th1/Tc1 cell responses via CD169-medicated $\mathrm{M} \varphi-\mathrm{T}$ cell interactions (unpublished observations). Surprisingly, we found that $\mathrm{CD} 169^{+} \mathrm{M} \varphi$ density was associated with shorter OS in UCB, although it was not an independent predictor in multivariate analysis. As CD169 can be co-expressed with CD204 on the same M $\varphi s$, a possible explanation for the detrimental effect of $\mathrm{M} \varphi \mathrm{s}$ on patient prognoses is that $\mathrm{M} \varphi$ with protumoral phenotypes (e.g., CD204) might be more prevalent than those with antitumoral phenotypes (e.g. CD169) in UCB tissues. Testing this hypothesis may be the subject of further investigations. 
The identification of pro- and anti-tumoral $\mathrm{M} \varphi$ phenotypes has largely been accomplished using in vitro or mouse models, while less evidence has been reported for their differential expression in human tissues in situ [28-29]. Our findings indicated that a potent protumoral $\mathrm{M} \varphi$ phenotype marker, CD204, and a potent antitumoral $\mathrm{M} \varphi$ phenotype marker, CD169, can be co-expressed on the same M $\varphi$ s in human UCB tissues. Moreover, the number of ST-infiltrating CD204-expressing M $\varphi$ s was positively correlated with disease progression and could potentially be used as a prognostic marker for UCB patients, despite the simultaneous presence of CD169-expressing M $\varphi s$.

\section{MATERIALS AND METHODS}

\section{Patients and tissue specimens}

Tissue specimens were obtained from January 2003 to December 2009 from 302 patients who had pathologically confirmed UCB at the Cancer Center of Sun Yat-sen University. No patient had a distant metastasis or received anticancer therapies prior to surgery, and none of them were treated with BCG immunotherapy after surgery. All tumors were graded according to the World Health Organization 2004 classification and staged according to the TNM classification $\left(6^{\text {th }}\right.$ edition, 2002). Patient clinicopathological characteristics are summarized in Table 3. All samples were anonymously coded in accordance with the local ethical guidelines (as stipulated by the Declaration of Helsinki). Written informed consent was obtained from all patients and the protocol was approved by the Review Board of the Cancer Center.

Patient follow-up data were obtained by the Cancer Center Tumor Registry, as described previously [30-32]. Briefly, patients were prospectively evaluated every
3 months during the first year, every 6 months during the second year, and annually thereafter. Follow-up visits consisted of a history, physical examination, and routine biochemical analyses. Ultrasonography of the abdomen, urography, and chest X-rays were performed at 3, 6, and 12 months postoperatively, and then annually unless otherwise clinically indicated. Abdominal/pelvic CT scans were performed 6 months postoperatively and annually thereafter. Bone scans were performed when clinically indicated. All tumor recurrences were histologically confirmed. Moreover, the survival status of all patients was updated by telephone contact in November 2014. The median follow-up for living patients was 82 months (range, 4-137 months). Overall survival (OS) was defined as the interval between surgery and death or between surgery and the last observation for surviving patients. Recurrence-free survival (RFS) was defined as the interval between surgery and recurrence or between surgery and the last observation for patients without recurrence. Among the 302 patients who were examined, 76 (25.2\%) died, 100 (33.1\%) had tumor recurrences, and 153 (51.7\%) remained alive without recurrence during the follow-up period.

\section{Immunohistochemistry}

Formalin-fixed and paraffin-embedded samples were cut into 5 - $\mu \mathrm{m}$ sections, which then were processed for immunohistochemistry as previously described [32]. Briefly, 5- $\mu \mathrm{m}$ thick paraffin sections were first deparaffinized and hydrated, then endogenous peroxidase activity was blocked by incubating the slides in $0.3 \%$ $\mathrm{H}_{2} \mathrm{O}_{2}$. Antigen retrieval was performed by microwave treatment in citrate buffer $(\mathrm{pH}$ 6.0). Sections were blocked with normal sera from the same species from which secondary antibodies were derived. After overnight

Table 3: Clinicopathological characteristics of urothelial cell carcinoma of the bladder patients

\begin{tabular}{|l|c|}
\hline Variable & No. \\
\hline No. of patients & $\mathbf{3 0 2}$ \\
\hline Age, years (median, range) & $60(15-90)$ \\
\hline Gender (male/female) & $262 / 40(86.8 \% / 13.2 \%)$ \\
\hline Tumor size ( $\leq 3 \mathrm{~cm} />3 \mathrm{~cm})$ & $235 / 67(77.8 \% / 23.2 \%)$ \\
\hline Multifocality (unifocal/multifocal ) & $214 / 88(70.9 \% / 29.1 \%)$ \\
\hline Tumor stage (Ta-T1/T2-T4) & $212 / 90(70.2 \% / 29.8 \%)$ \\
\hline Nodal metastasis (N0/N1-N2) & $286 / 16(94.7 \% / 5.3 \%)$ \\
\hline Histological grade (low/high) & $175 / 127(57.9 \% / 42.1 \%)$ \\
\hline Follow-up, months (median, range) & $82(4-137)$ \\
\hline
\end{tabular}


incubation at $4{ }^{\circ} \mathrm{C}$ with antibodies against human $\alpha$-SMA (1:500 dilution, Zhongshan Bio-Tech Co., Zhongshan, China), CD68 (1:500 dilution, Dako A/S, Glostrup, Copenhagen, Denmark), CD169 (1:200 dilution, R\&D Systems, Minneapolis, MN, USA), CD204 (1:500, dilution, Transgenic, Kumamoto, Japan), or control antibodies (Santa Cruz Biotechnology, Santa Cruz, CA, USA), sections were incubated with secondary antibodies conjugated to horseradish peroxidase (Envision + Dual Link Kit, DAKO, for mouse/rabbit antibodies; or R\&D Systems for donkey anti-sheep secondary antibody) for $30 \mathrm{~min}$. The enzymatic reactions were developed using a peroxidase-labeled secondary antibody followed by 3,3'-diaminobenzidine tetrahydrochloride using the Envision System (Dako). Sections were counterstained with hematoxylin (Zymed Laboratories, San Francisco, CA, USA) and mounted in nonaqueous mounting medium.

\section{Immunofluorescence}

For immunofluorescence staining, paraffinembedded tissue sections were first incubated with rabbit anti-human CD68 and mouse anti-human CD204, or/and sheep anti-human CD169, followed by incubation with specimen-paired immunofluorescence secondary antibodies (Life Technologies). Isotype-matched primary antibodies were used as negative controls. Images were captured and analyzed on a Zeiss LSM710 system using ZEN software (Zeiss, Oberkochen, Germany).

\section{Evaluation of immunohistology}

Tissue sections were analyzed by two independent observers who were blinded to the clinical outcome. The localization patterns of infiltrating cells in the tumors were divided into two different regions, defined as the intratumoral (INT) and stromal (ST) regions. Anti- $\alpha-S M A$ antibody was used to facilitate the identification of tumor ST regions, as described previously [24]. To evaluate the

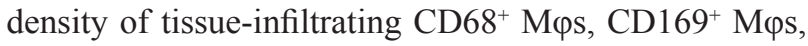
and $\mathrm{CD} 204^{+} \mathrm{M} \varphi s$, tissue sections were screened at a lowpower field $(100 \times)$ and the five most representative fields were selected for analysis at $400 \times$ magnification $\left(0.07 \mathrm{~mm}^{2}\right.$ per field) using a Nikon DS-Fi2 CCD camera (Nikon, Tokyo, Japan) that was installed on a Nikon Eclipse $80 i$ microscope (Nikon, Tokyo, Japan). The infiltrating cells per field were enumerated manually and counts were expressed as means \pm SEM. A significant linear correlation existed between the counts of two independent observers and the average count of the two investigators was used in subsequent analyses to minimize inter-observer variability.

\section{Statistical analyses}

Statistical analyses were performed using SPSS 13.0 software (SPSS Inc., Chicago, IL, USA). The statistical significance of differences between groups was determined using the Wilcoxon signed-rank test. Cumulative survival time was calculated using the Kaplan-Meier method and was analyzed by the log-rank test. A multivariate Cox proportional hazards model was used to estimate the adjusted hazard ratios and $95 \%$ confidence intervals (CIs), and to identify independent prognostic factors. For categorical analyses, the median value was used as a cut-off to dichotomize continuous variables (for clinical applications). Associations between variables were analyzed using Spearman $\rho$ coefficient tests and relationships between categorical variables were analyzed using $\chi^{2}$ tests. For such comparisons, two-tailed $P$-values $<0.05$ were considered to indicate statistically significant differences.

\section{ACKNOWLEDGMENTS}

This study was funded by grants from China Postdoctoral Science Foundation (Grant No. 2014M562241), the National Natural Science Foundation of China (Grant Nos. 81402106, U1301221, 81472384, 81372729, 81372883, 81272808, 81172431, 81101935), Guangdong Province Natural Scientific Foundation (Grant No. S2013020012671, 07117336, 10151008901000024), the Specialized Research Fund for the Doctoral Program of Higher Education (for Tianxin Lin, 20130171110073), the Sun Yat-Sen University Clinical Research 5010 Program (Grant No. 2007018), the Elite Young Scholars Program of Sun Yat-Sen Memorial Hospital (for Tianxin Lin, J201401), the National Clinical Key Specialty Construcion Project for Department of Urology, Grant KLB09001 from the Key Laboratory of Malignant Tumor Gene Regulation and Target Therapy of Guangdong Higher Education Institutes, Sun-Yat-Sen University and Grant [2013] 163 from Key Laboratory of Malignant Tumor Molecular Mechanism and Translational Medicine of Guangzhou Bureau of Science and Information Technology.

\section{CONFLICTS OF INTEREST}

No potential conflicts of interest were disclosed.

\section{REFERENCES}

1. Jacobs BL, Lee CT, Montie JE. Bladder cancer in 2010: how far have we come? CA Cancer J Clin. 2010; 60:244-272.

2. Babjuk $M$, Burger $M$, Zigeuner $R$, Shariat SF, van Rhijn BW, Comperat E, Sylvester RJ, Kaasinen E, Bohle A, Palou Redorta J, Roupret M. EAU guidelines on nonmuscle-invasive urothelial carcinoma of the bladder: update 2013. Eur Urol. 2013; 64:639-653. 
3. Redelman-Sidi G, Glickman MS, Bochner BH. The mechanism of action of BCG therapy for bladder cancera current perspective. Nat Rev Urol. 2014; 11:153-162.

4. Bevers RF, Kurth KH, Schamhart DH. Role of urothelial cells in BCG immunotherapy for superficial bladder cancer. Br J Cancer. 2004; 91:607-612.

5. Mueller MM, Fusenig NE. Friends or foes - bipolar effects of the tumour stroma in cancer. Nat Rev Cancer. 2004; 4:839-849.

6. Hanahan D, Coussens LM. Accessories to the crime: functions of cells recruited to the tumor microenvironment. Cancer Cell. 2012; 21:309-322.

7. Murray PJ, Allen JE, Biswas SK, Fisher EA, Gilroy DW, Goerdt S, Gordon S, Hamilton JA, Ivashkiv LB, Lawrence T, Locati M, Mantovani A, Martinez FO, Mege JL, Mosser DM, Natoli G, et al. Macrophage Activation and Polarization: Nomenclature and Experimental Guidelines. Immunity. 2014; 41:14-20.

8. Pollard JW. Tumour-educated macrophages promote tumour progression and metastasis. Nat Rev Cancer. 2004; 4:71-78.

9. Qian BZ, Pollard JW. Macrophage diversity enhances tumor progression and metastasis. Cell. 2010; 141:39-51.

10. Mantovani A, Biswas SK, Galdiero MR, Sica A, Locati M. Macrophage plasticity and polarization in tissue repair and remodelling. J Pathol. 2013; 229:176-185.

11. Lewis CE, Pollard JW. Distinct role of macrophages in different tumor microenvironments. Cancer Res. 2006; 66:605-612.

12. Laoui D, Movahedi K, Van Overmeire E, Van den Bossche J, Schouppe E, Mommer C, Nikolaou A, Morias Y, De Baetselier P, Van Ginderachter JA. Tumor-associated macrophages in breast cancer: distinct subsets, distinct functions. Int J Dev Biol. 2011; 55:861-867.

13. Xu L, Zhu Y, Chen L, An H, Zhang W, Wang G, Lin Z, $\mathrm{Xu}$ J. Prognostic value of diametrically polarized tumorassociated macrophages in renal cell carcinoma. Ann Surg Oncol. 2014; 21:3142-3150.

14. Bowdish DM, Gordon S. Conserved domains of the class A scavenger receptors: evolution and function. Immunol Rev. 2009; 227:19-31.

15. Komohara Y, Hasita H, Ohnishi K, Fujiwara Y, Suzu S, Eto M, Takeya M. Macrophage infiltration and its prognostic relevance in clear cell renal cell carcinoma. Cancer Sci. 2011; 102:1424-1431.

16. Kaku Y, Imaoka H, Morimatsu Y, Komohara Y, Ohnishi K, Oda H, Takenaka S, Matsuoka M, Kawayama T, Takeya M, Hoshino T. Overexpression of CD163, CD204 and CD206 on alveolar macrophages in the lungs of patients with severe chronic obstructive pulmonary disease. PLoS One. 2014; 9:e87400.

17. Sugimoto M, Mitsunaga S, Yoshikawa K, Kato Y, Gotohda N, Takahashi S, Konishi M, Ikeda M, Kojima M, Ochiai A, Kaneko H. Prognostic impact of M2 macrophages at neural invasion in patients with invasive ductal carcinoma of the pancreas. Eur J Cancer. 2014; 50:1900-1908.

18. O'Neill AS, van den Berg TK, Mullen GE. Sialoadhesin a macrophage-restricted marker of immunoregulation and inflammation. Immunology. 2013; 138:198-207.

19. Klaas M, Crocker PR. Sialoadhesin in recognition of self and non-self. Semin Immunopathol. 2012; 34:353-364.

20. Asano K, Nabeyama A, Miyake Y, Qiu CH, Kurita A, Tomura M, Kanagawa O, Fujii S, Tanaka M. CD169positive macrophages dominate antitumor immunity by crosspresenting dead cell-associated antigens. Immunity. 2011; 34:85-95.

21. Balkwill FR, Capasso M, Hagemann T. The tumor microenvironment at a glance. J Cell Sci. 2012; 125:5591-5596.

22. Martinez FO, Gordon S. The M1 and M2 paradigm of macrophage activation: time for reassessment. F1000Prime Rep. 2014; 6:13.

23. Hanada T, Nakagawa M, Emoto A, Nomura T, Nasu N, Nomura Y. Prognostic value of tumor-associated macrophage count in human bladder cancer. Int J Urol. 2000; 7:263-269.

24. Sjodahl G, Lovgren K, Lauss M, Chebil G, Patschan O, Gudjonsson S, Mansson W, Ferno M, Leandersson K, Lindgren D, Liedberg F, Hoglund M. Infiltration of CD3 and CD68 cells in bladder cancer is subtype specific and affects the outcome of patients with muscle-invasive tumors. Urol Oncol. 2014; 32:791-797.

25. Wu Y, Zheng L. Dynamic education of macrophages in different areas of human tumors. Cancer Microenviron. 2012; $5: 195-201$.

26. Galon J, Costes A, Sanchez-Cabo F, Kirilovsky A, Mlecnik B, Lagorce-Pages C, Tosolini M, Camus M, Berger A, Wind P, Zinzindohoue F, Bruneval P, Cugnenc PH, Trajanoski Z, Fridman WH, Pages F. Type, density, and location of immune cells within human colorectal tumors predict clinical outcome. Science. 2006; 313:1960-1964.

27. Neyen C, Pluddemann A, Mukhopadhyay S, Maniati E, Bossard M, Gordon S, Hagemann T. Macrophage scavenger receptor a promotes tumor progression in murine models of ovarian and pancreatic cancer. J Immunol. 2013; 190:3798-3805.

28. Kuang DM, Zhao Q, Peng C, Xu J, Zhang JP, Wu C, Zheng L. Activated monocytes in peritumoral stroma of hepatocellular carcinoma foster immune privilege and disease progression through PD-L1. J Exp Med. 2009; 206:1327-1337.

29. Ohri CM, Shikotra A, Green RH, Waller DA, Bradding P. Macrophages within NSCLC tumour islets are predominantly of a cytotoxic M1 phenotype associated with extended survival. Eur Respir J. 2009; 33:118-126.

30. Huang J, Lin $\mathrm{T}$, Liu $\mathrm{H}, \mathrm{Xu} \mathrm{K}$, Zhang $\mathrm{C}$, Jiang $\mathrm{C}$, Huang H, Yao Y, Guo Z, Xie W. Laparoscopic radical 
cystectomy with orthotopic ileal neobladder for bladder cancer: oncologic results of 171 cases with a median 3-year follow-up. Eur Urol. 2010; 58:442-449.

31. Liu J, Cai M, Chen J, Liao Y, Mai S, Li Y, Huang X, Liu Y, Zhang J, Kung H, Zeng Y, Zhou F, Xie D. alpha4 contributes to bladder urothelial carcinoma cell invasion and/or metastasis via regulation of E-cadherin and is a predictor of outcome in bladder urothelial carcinoma patients. Eur J Cancer. 2014; 50:840-851.

32. Wang B, Shaoxu W, Zeng H, Liu Z, Dong W, Wang H, Chen X, Dong X, Zheng L, Lin T, Huang J. CD103 tumorinfiltrating lymphocytes predict a favorable prognosis in urothelial cell carcinoma of the bladder. J Urol. 2015; pii: S0022-5347:03268-1. 